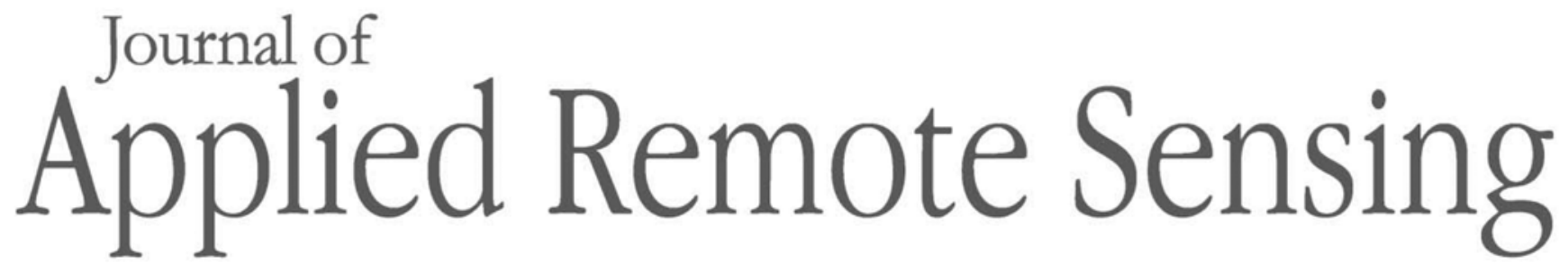

RemoteSensing.SPIEDigitalLibrary.org

\title{
Spatiotemporal variations of forest phenology in the Qinling Mountains and its response to a critical temperature of $10^{\circ} \mathrm{C}$
}

\author{
Zhao Wang \\ Chunfang Xue \\ Wenting Quan \\ Huijuan $\mathrm{He}$
}




\title{
Spatiotemporal variations of forest phenology in the Qinling Mountains and its response to a critical temperature of $10^{\circ} \mathrm{C}$
}

\author{
Zhao Wang, ${ }^{\mathrm{a}, *}$ Chunfang Xue, ${ }^{\mathrm{b}}$ Wenting Quan, ${ }^{\mathrm{a}}$ and Huijuan $\mathrm{He}^{\mathrm{a}}$ \\ ${ }^{a}$ Shaanxi Remote Sensing Information Center for Agriculture, Xi' an, China \\ ${ }^{\mathrm{b}}$ Shaanxi Meteorological Bureau, Xi'an, China
}

\begin{abstract}
Based on the fifth version MOD09A1 product of NASA LP DAAC (Land Processes Distributed Active Center) from 2001 to 2016, an enhanced vegetation index (EVI) time series dataset in the Qinling Mountains was reconstructed; it was used to extract the plant phenological parameters of the region by employing the maximal slopes of the alteration method and threshold method. The results show that the Whittaker filter method was better than other methods for the reconstruction of shrubland, farmland, and forest in the Qinling Mountains. Based on the reconstructed EVI, the characteristics of vegetation coverage, the start of growth season (SOG), the end of growth season (EOG), and the length of growth season (LOG) in the Qinling Mountains were all analyzed. There was an increasing trend of vegetation coverage in most regions (about 89.93\% of the monitored areas) over the Qinling Mountains in the past decades, and the average phenological distribution pattern in the Qinling Mountains was closely related to the local hydrothermal conditions. From the high altitude mountainous areas to the farming areas, the SOG was gradually postponed, the EOG was gradually earlier, and the LOG gradually shortened. Furthermore, the time series variation of SOG, EOG, and LOG from 2001 to 2016 in the Qinling Mountains was also studied. The variation showed that the SOG shifted earlier, which was more prominent in high-altitude areas, while, for some southern and northern foothills altitude below $500 \mathrm{~m}$ and a few areas of the eastern Funiu Mountains, the SOG was delayed. The EOG shifted later, which was more apparent in the northern Qinling foothills and mid- to low-altitude areas of the eastern ranges, and the LOG was extended. Finally, the studies of correlation analysis between the plant phenology and a temperature threshold of $10^{\circ} \mathrm{C}$ showed that global warming was the major factor affecting the phytophenology of the Qinling Mountains, and the effects were concentrated mainly in the 1000- to 2000-m zones of the southern and northern Qinling Mountains. Moreover, the northern Qinling foothills showed a greater response to accumulated temperature than the southern foothills, and the low-altitude area of the eastern Funiu Mountains exhibited the lowest correlation with the accumulated temperature. (C) The Authors. Published by SPIE under a Creative Commons Attribution 3.0 Unported License. Distribution or reproduction of this work in whole or in part requires full attribution of the original publication, including its DOI. [DOI: 10.1117/1.JRS.12.022202]
\end{abstract}

Keywords: Qinling Mountains; phenology; start of growth season; end of growth season; length of growth season.

Paper 170763SS received Aug. 30, 2017; accepted for publication Sep. 19, 2017; published online Jan. 16, 2018.

\section{Introduction}

Phenology refers to periodic changes of organisms after their long-term adaptation to climate conditions, thereby developing corresponding growth and development cycles. Phenology is the most intuitive indicator for the response of ecosystems to climate change. By studying forest phenology, we can understand the influences of climate change on the species composition and

*Address all correspondence to: Zhao Wang, E-mail: sandstom@163.com 
physiology of trees and on forest productivity, which are of vital importance for the conservation of biodiversity. As such, phenology is a hot topic in geology research, particularly large-scale vegetation surveillance, which is a key field in phenology that addresses a crucial scientific question of ecological and environmental studies. ${ }^{1,2}$ Common methods of phenology surveillance include ground observation, remote sensing, and model-based surveillance. Among them, ground observation has high time precision and is easy to operate for small-scale phenology studies, but it has difficulty revealing phenology conditions at a regional scale. Satellites remote sensing technology can remedy defects of ground observation. Atzberger and Eilers, ${ }^{3}$ Beck et al., ${ }^{4}$ Chen et al., ${ }^{5}$ Sakamoto et al., ${ }^{6}$ Yves and Sobrino, ${ }^{7}$ Wang et al., ${ }^{8}$ White et al., ${ }^{9}$ and Zhang et al. ${ }^{10}$ used satellites data to monitor the vegetation activity and phenology over different areas. Since the threshold method was reported to extract phytophenological parameters in $1990,{ }^{11}$ remote sensing-based phenology surveillance has been applied in a variety of fields, including biodiversity, land cover classification, estimation of crop yield, and biomass assessment. Correspondingly, phenology has become an effective tool for studying terrestrial ecosystems. Many studies have been devoted to investigating approaches for extracting phenological parameters based on remote sensing data, such as the normalized difference vegetation index (NDVI)-based threshold method and the maximal slope of alteration method that are indicative of vegetative types. Meanwhile, the relationship between the phenological information of remote sensing monitoring and the actual observation data of terrestrial stations has received increasing attention. It was reported that, through the use of ground observation data as well as NVDI datasets of Landsat and MODIS, different sources of remote sensing results could be used to describe the observation data of ground phenology in an area. ${ }^{12}$ A study by Kross et al. ${ }^{13}$ indicated that an NDVI dataset with a time resolution of 10 or 15 days was suitable for extracting phenological information from ground vegetation. Atkinson et al. ${ }^{14}$ compared four models for smoothing satellite sensor time-series data to estimate vegetation phenology. It has been demonstrated that over the last several decades, the plant growth seasons in the northern hemisphere have gradually extended, which leads to an increase in carbon sequestration in highlatitude areas. ${ }^{15}$ In China, many studies show similar trends in most regions using ground observation and satellite monitoring, Fang et al. ${ }^{16}$ and Zheng et al. ${ }^{17}$ discussed the effect of global warming on plant phenological changes, and the results show that the response of ahead (or delay) of phenophase to increasing (or decreasing) of temperature was nonlinear. Zhang, ${ }^{18}$ Lu et al., ${ }^{19} \mathrm{Li}$ et al., ${ }^{20} \mathrm{He}$ et al., ${ }^{21}$ Fang et al., ${ }^{22}$ Zhong et al., ${ }^{23}$ Wang et al., ${ }^{24}$ and Xie et al. ${ }^{25}$ studied the trend of plant phenology and its responses to climatic change over different areas in China.

The Qinling Mountains lie in central China and are at the ecological transition belt between the warm temperature zone and subtropical zone. The mountain range, which is the geological boundary between southern and northern China, has two very different definitions. In the broad definition, the Qinling Mountains join the Kunlun Mountains in the west, connect the Minshan Mountains in the north, and travel eastward through Gansu, southern Shaanxi, to reach the Funiu Mountains in Henan in the east; in the narrow definition, Qinling refers to mountains between the Wei River and Han River in Shaanxi Province. In recent years, progressive urbanization and increased human activity have aggravated vegetation degeneration in some areas. ${ }^{26,27}$ Although the alpine vegetation that is present at altitudes above $2800 \mathrm{~m}$ is barely affected by any human activity, it is highly impacted by climate change. Thus far, considerable effort has been dedicated to examining the phytophenological responses in areas of different altitudes in the Qinling Mountains, ${ }^{28-30}$ and vegetation degeneration, its causes, and spatiotemporal changes of phenology in the Qinling Mountains have been analyzed. However, although spatiotemporal changes of phenology have been examined in the Qinling Mountains, there has been no thorough investigation into the causes of phenological changes and the resultant responses to climate change, which is due to the short or overly macroscopic time series. Here, we utilized satellite data from 2001 to 2016 to extract the phenological changes of different altitudes in the Qinling Mountains. In addition, we employed a biological threshold temperature of $10^{\circ} \mathrm{C}$ to analyze the causes of the phenological changes. As such, the study provides crucial evidence to understand the phytophenological response features at different altitudes that are under the dual influence of human activity and climate change. 


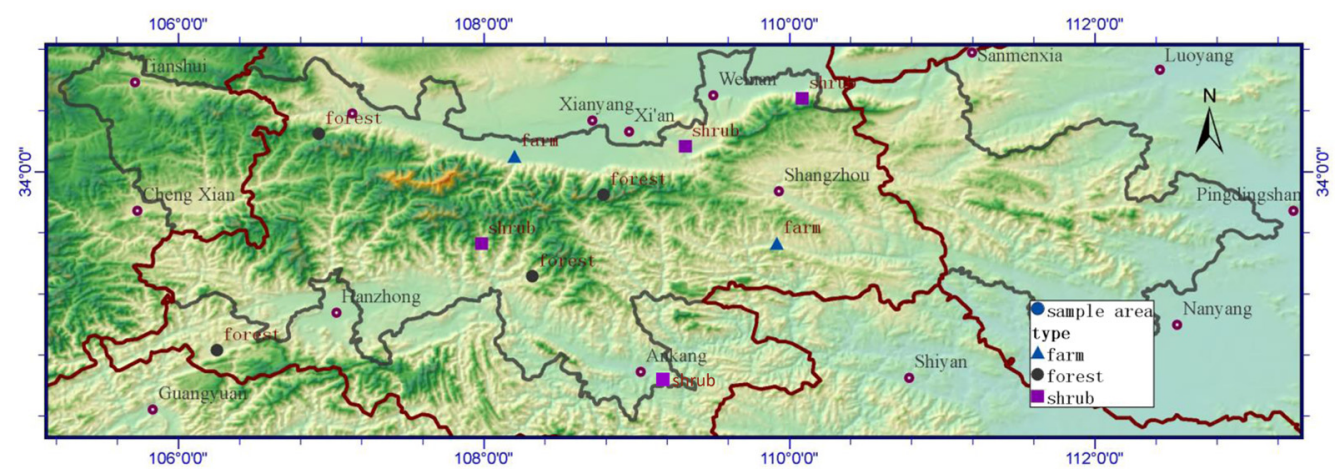

Fig. 1 Topographic map and land use types of the Qinling Mountains.

\section{General Conditions of the Study Region}

The Qinling Mountains in a broad sense include 43 counties in Gansu, Shaanxi, and Henan provinces. ${ }^{31}$ It stretches over $700 \mathrm{~km}$, and there are many interconnected mountains, including Xiaolong Mountain, Taibai Mountain, Xiong'er Mountain, Huashan Mountain, and the Funiu Mountains. Overall, the orientation of the Qinling Mountains matches well with the $0^{\circ} \mathrm{C}$ isotherm of January. With an annual average temperature of $12^{\circ} \mathrm{C}$ to $14^{\circ} \mathrm{C}$ and precipitation of 700 to $900 \mathrm{~mm}$, the mountain range has a rich coverage of vegetation, including forest and grassland in the high-altitude areas and farmland in low-altitude valleys. The central hills boast extraordinary altitude differences that accommodate a spectrum of vegetation types, which are the farming area (altitude 200 to $700 \mathrm{~m}$ ), deciduous broad-leaved forest belt (altitude 700 to $1300 \mathrm{~m}$ ), deciduous oak forest belt (altitude 1300 to $2300 \mathrm{~m}$ ), birch forest belt (altitude 2300 to $2800 \mathrm{~m}$ ), coniferous forest belt (altitude 2800 to $3200 \mathrm{~m}$ ), and alpine shrub-meadow belt (above altitude $3200 \mathrm{~m}$ ). The coniferous forest belt, which represents the high-altitude limit of the forest, is dominant with Farges' fir (Abies fargesii) forest and Shaanxi larch (Larix potaninii var. chinensis) forest. In addition, there is a little distribution difference spectrum of vegetation types between the southern and northern Qinling hills, which is attributed to the relevant climate differences. ${ }^{32}$ To improve validation accuracy, nine classical ecological sample plots were selected based on high-resolution land use data (Fig. 1) and ground survey data to represent the various vegetation types of the forest, shrubland, and farmland (Table 1). Among these,

Table 1 Ecological types of the sample plots in the Qinling Mountains.

\begin{tabular}{llllc}
\hline \hline No. & Location & Ecological type & \multicolumn{1}{c}{ Classical vegetation } & Altitude $(\mathrm{m})$ \\
\hline 1 & Huashan & Shrubland & Vitex, wild jujube, shrubs & 1694 \\
2 & Lantian & Shrubland & Vitex, wild jujube, shrubs & 520 \\
3 & Foping & Shrubland & Vitex, wild jujube, shrubs & 852 \\
4 & Zhenping & Shrubland & Azalea, sea bilberry, Chinese red pine forest & 1094 \\
5 & Zhouzhi & Farmland & $\begin{array}{l}\text { Dry farming with two harvests per year, } \\
\text { deciduous fruit trees, shelter forests of aspen, } \\
\text { willow, and Chinese scholar trees }\end{array}$ & 463 \\
6 & Shanyang & Farmland & Dry and irrigated farming with two harvests per year & 783 \\
7 & Ninqiang & Forest & Chinese red pine forest & 787 \\
8 & Ninshan & Forest & Chinese red pine forest, Chinese red birch forest, & 2630 \\
& & Fhinese hemlock forest, Farges' fir forest & 1576 \\
\hline \hline
\end{tabular}


Ninshan, with an altitude of $2630 \mathrm{~m}$, is a national field observation station of a coniferous forest of the Qinling ecological system (Table 1).

\section{Data and Methods}

\subsection{Satellite Data}

The fifth version MOD09A1 product from 2001 to 2016 was provided by NASA LP DAAC (Land Processes Distributed Active Archive Center); it included surface albedo bands 1 to 7, day of year (DoY) data, an 8-day time resolution, and a 500-m spatial resolution. In this study, the MODO09A1 product was used to generate pixels with the best observation quality in an 8-day interval. After atmospheric correction, the Qinling Mountains were found to be located in the H26V5 and H27V5 tiles. From 2001 to 2016, a total of 736 MOD09A1 images were generated, and all were subject to SIN GRID projection. To remove the influences of nonforest areas, we used the MOD12Q1 land cover data of 2012 to reveal that forest and farmland accounted for over $95 \%$ of the total area.

The linear tendency method was used for the trend analysis; when $B>0$, an increase of time $T$ was associated with an increase of $X$; the value of $B$ indicated the rate (or tendency) of ascent or descent [Eq. (1)]:

$$
B=\frac{\sum_{i=1}^{n} x_{i} t_{i}-\frac{1}{n} \sum_{i=1}^{n} x_{i} \sum_{i=1}^{n} t_{i}}{\sum_{i=1}^{n} t_{i}^{2}-\frac{1}{n}\left(\sum_{i=1}^{n} t_{i}\right)^{2}},
$$

where $B$ is the slope of linear tendency, $x$ is parameter of phenology, $t$ is the year of phenology, and $n=15$.

The coefficient of variation $\left(C_{v}\right)$ was used to evaluate the time series stability; it indicated a degree of dispersion such that the lower the $C_{v}$, the lower the fluctuation [Eq. (2)]:

$$
C_{v}=\frac{1}{x} \sqrt{\frac{\sum_{i=1}^{n}\left(x_{i}-\bar{x}\right)^{2}}{n-1}}
$$

where $C_{v}$ is the coefficient of enhanced vegetation index (EVI) variation, $x_{i}$ is the EVI of the $i$ year, and $\bar{x}$ is the average of EVI from 2001 to 2016.

The correlation coefficient $(R)$ reflected the ability of the reconstructed time series curve to retain the features of the corresponding original curve; the greater the value is, the higher the reconstruction fidelity [Eq. (3)]:

$$
R=\frac{\sum_{i=1}^{n}\left(x_{i}-\bar{x}\right)\left(y_{i}-\bar{y}\right)}{\sqrt{\sum_{i=1}^{n}\left(x_{i}-\bar{x}\right)^{2} \sum_{i=1}^{n}\left(y_{i}-\bar{y}\right)^{2}}} .
$$

The standard error of the regression estimate (regression mean squared error, RMSE) was employed to describe the differential level between the individual time series; the lower the value is, the greater the representatively of the fitted value [Eq. (4)]:

$$
\mathrm{RMSE}=\sqrt{\frac{\sum_{i=1}^{n}\left(\mathrm{EVI}_{p i}-\mathrm{EVI}_{o i}\right)^{2}}{n}},
$$

where $\mathrm{EVI}_{p i}$ is reconstruction series data, $\mathrm{EVI}_{o i}$ is original series data, and $n$ is the number of samples.

\subsection{Calculation of the Vegetation Index}

This study analyzed the MODIS MOD13Q1 product with a 16-day interval, and it showed that when the NDVI of the high-vegetation coverage areas in the Qinling Mountains approached 0.8, the fluctuation decreased, which indicated that the chlorophyll responses of the vegetation 
reached saturation. This result was consisted with the previous report. ${ }^{33}$ Fortunately, the EVI avoids the saturation issue of high-vegetation coverage areas and reduces the background noises of the atmosphere and soil. In addition, the EVI uses a time resolution of 8 days, which is considerably better than the 16-day resolution. As such, we utilized interactive data language along with the MRT tool of MODLAND to write the batch program, whereby the reflectivity data and DoY bands in the MODIS tiles of H26V5 and H27V5 were pieced together and projected. Correspondingly, the data were converted to coordinate projections of latitude and longitude in the WGS-84 coordinate system. The EVI was calculated using Eq. (5):

$$
\mathrm{EVI}=2.5 * \frac{\rho_{\mathrm{NIR}}-\rho_{\mathrm{RED}}}{\rho_{\mathrm{NIR}}+6 * \rho_{\mathrm{RED}}-7.5 \rho_{\mathrm{BLUE}}+1}
$$

in which $\rho_{1}, \rho_{2}$, and $\rho_{3}$ represent the reflection values of the infrared, red, and blue bands, respectively, after atmospheric correction from the MODIS sensor, $G(=2.5)$ represents the gain factor, $L(=1)$ represents the soil-adjusted index, and $C_{1}(=6.0)$ and $C_{2}(=7.5)$ describe the influences of the blue-band correction on the red band. To further improve time precision, the DoY values of pixels were interpolated into day values during reconstruction of the time series, thereby avoiding the fluctuation of crests and troughs around the 8-day intervals.

\subsection{Reconstruction of the EVI Time Series}

To minimize the influences of random factors on the time series, a time series reconstruction was needed. ${ }^{34-39}$ Common algorithms for this purpose include the filter smoothing method (e.g., the Savitzky-Golay filter ${ }^{40}$ and Whittaker filter) ${ }^{30}$ the function fitting method [also known as asymmetric Gaussian (AG)], double logistic (DL) function-fitting, and the frequency-domain transformation method [e.g., harmonic analysis of time series (HANTS), and wavelet analysis]. Different methods have different requirement stringencies on the original time series and are therefore suitable for different environmental conditions. In the Qinling Mountains, where there are considerable levels of data noise, the Whittaker, DL, HANTS, and AG methods were chosen to reconstruct the time series. Afterward, the resulting fidelity and antijamming capability were analyzed for individual sample plots to determine the optimal approach for each ecological type.

\subsubsection{Quantitative comparison of the reconstruction algorithms}

Based on the correlation performance and RMSE values of the four methods that were used to reconstruct the time series of shrubland, farmland, and forest (Fig. 2) from 2001 to 2016, the results showed that the Whittaker method exhibited a better correlation performance than the DL and AG methods, whereas the HANTS method showed a relatively poor outcome. Also, an examination of the RMSE values showed that the Whittaker method showed the lowest deviation
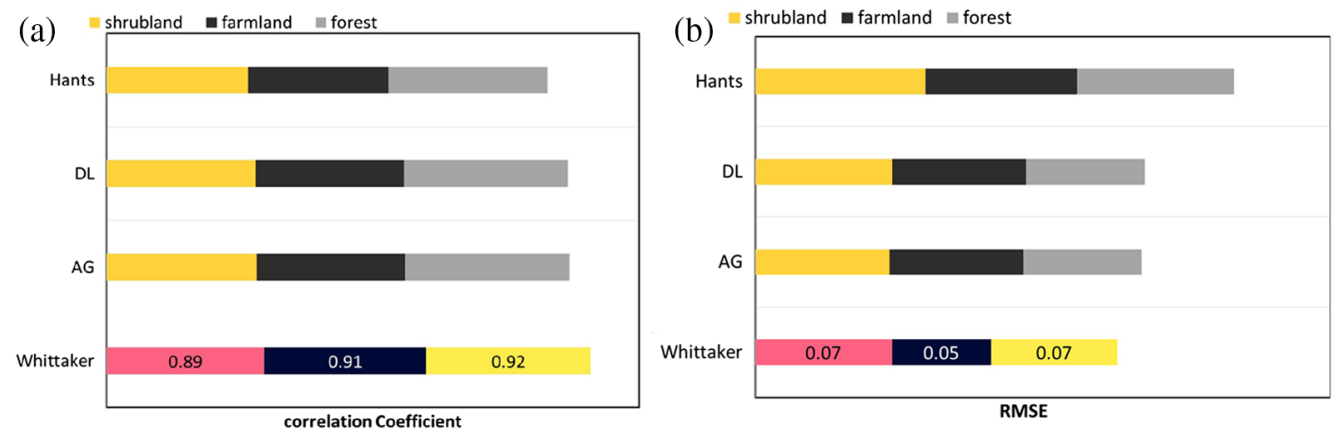

Fig. 2 The (a) correlation performances and (b) RMSE values of the Whittaker, DL, HANTS, and AG methods for the time series reconstruction of three ecological types in the Qinling Mountains. 
between the reconstructed and original EVI values, indicating that this method generated the best fitting performance, better than DL and AG, and the HANTS methods displayed a relatively poor outcome.

\subsubsection{Comparison of the time series curves of several reconstruction algorithms}

Figure 3 showed the comparison of the time series curves of original EVI data from 2014 to 2016 reconstruction data derived from the four methods. The results showed that, in the shrub-land, the Whittaker, DL, AG, and HANTS methods displayed similar levels of fitting, but, in the peak value, the Whittaker method showed clearly superior antijamming performance over the other methods, as it delivered better fitting outcomes at points with considerable noise levels. In the farmland sample plots, the HANTS, AG, and DL methods generated fitting results that were relatively high in the early growth phase, although in the middle and peak growth stages, all four methods produced consistent fitting results that matched the original EVI time series curves.

(a)

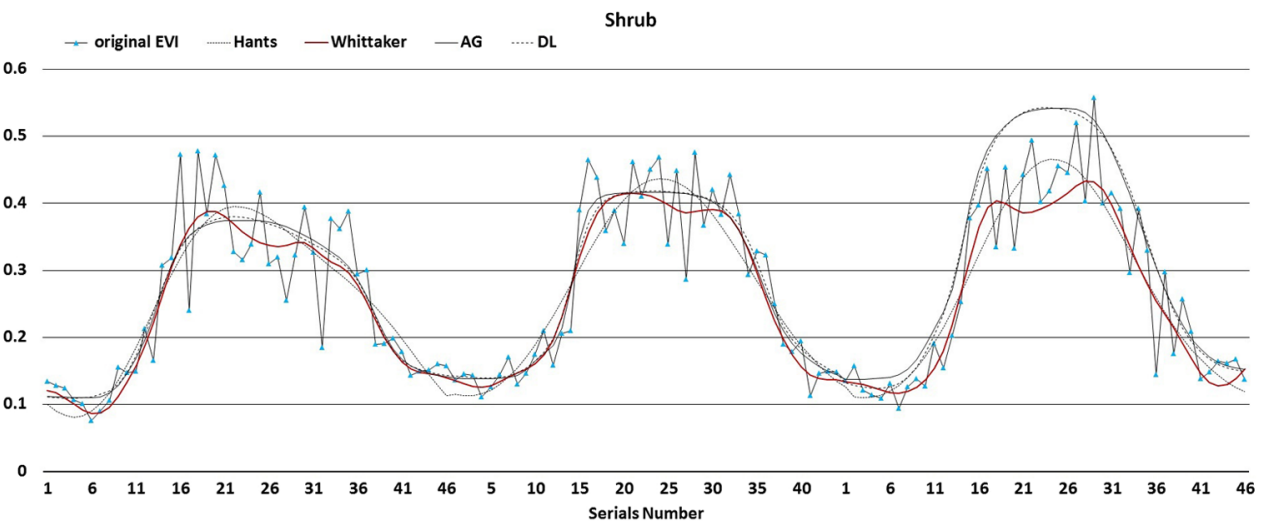

(b)

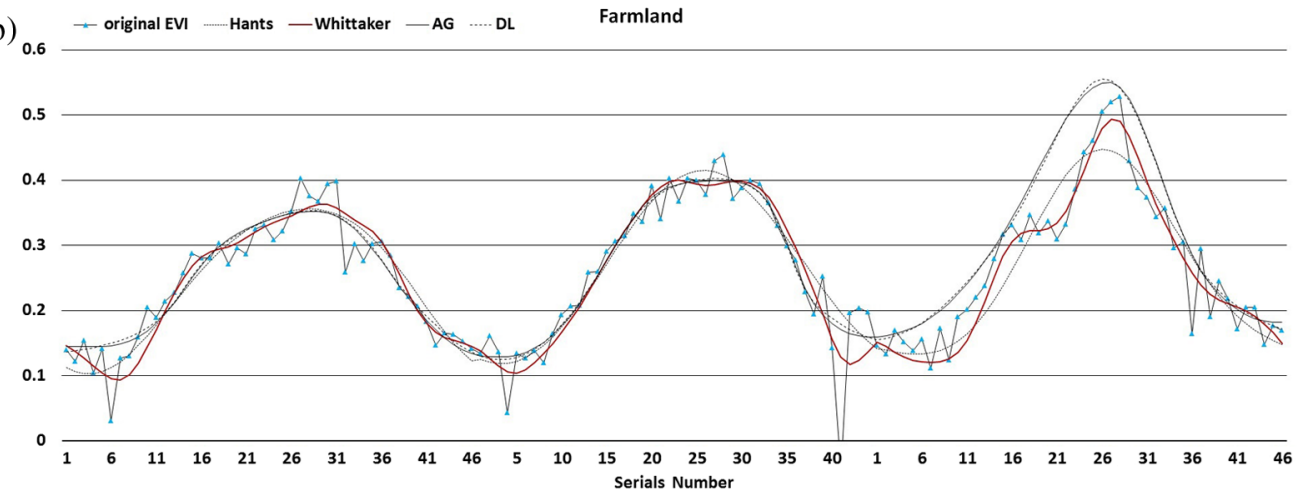

(c)
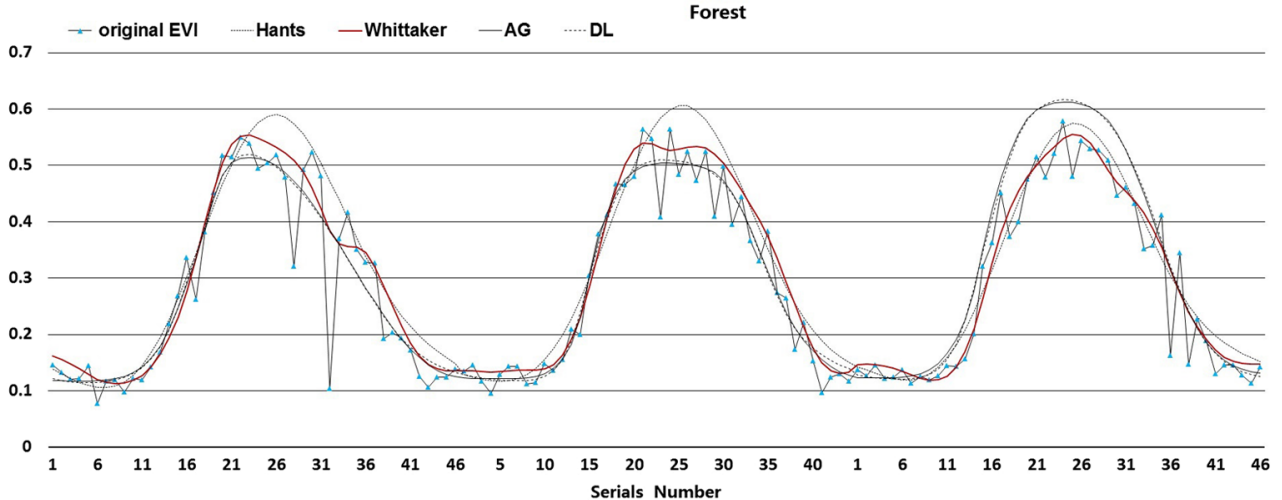

Fig. 3 The reconstructed EVI curves of the sample plots of (a) shrubland, (b) farmland, and (c) forest. 
All three filtering methods except the Whittaker displayed excessive fitting in the crest period of 2016 and produced a single peak, whereas Whittaker-based fitting generated a dual-peak curve that was consistent with the original data. In the forest sample plots, the four methods generated similar fitting results in the early growth phase and end of growth season (EOG), but the HANTS produced relatively high fitting results in the crest period of 2014 to 2015 due to noise interference, as did the AG and DL in 2016. By contrast, the Whittaker generated a curve that was consistent with the original EVI time series curve.

In general, the Whittaker method displayed the most stable performance among the four methods and is suitable for use in the Qinling Mountains, which is consistent with the finding by Atkinson. ${ }^{14}$

\subsection{Extraction of Phenological Parameters}

The methods to extract phenological parameters include the threshold method, ${ }^{40}$ maximal slope of alteration, ${ }^{41}$ and the logistics function method ${ }^{42,43}$ The Qinling Mountains have extraordinary altitude differences, application of the threshold method alone may not adequately reflect topological influences. To avoid this problem, the threshold method was also used with the maximal slop of alteration to extract the phenological parameters. First, the Whittaker filter was employed to reconstruct the daily means of EVI data from 2001 to 2016; then the differences between adjacent points were calculated to generate an EVI difference curve. Subsequently, the maximal change value of the upswing (or downswing) curve is taken as the EVI threshold of the SOG (or EOG). Finally, year-by-year sequences of daily values were compared with the corresponding threshold value to generate the SOG and EOG, which were subtracted to generate the length of growth season (LOG).

\subsection{Accuracy Validation of the Phenological Extraction in the Qinling Mountains}

A traditional and straightforward approach to validating the accuracy of the phenological extraction is to adopt the occurrence dates of a given phenological phenomenon as the validation data. In an area of limited size, there is a certain level of similarity in the plant phenophase of a particular vegetation type. The Qinling Botanic Garden of Xi'an is located in the northern foothills of the mountain range and is representative of the local phenology. We therefore acquired typical phenological data of woody plants in the Xi'an station during 1963 to 2008 and adopted the daily average of their peak leafing period as the SOG and their leaf color-change period as the EOG. It was discovered that the peak leafing period was predominantly concentrated in the first 10 days of April (the 95th to 100th days of each year), whereas all the color-change periods were in the first 10 days of November (the 300th to 310th days). With regard to multiyear trends, it was reported that the peak leafing period advanced earlier by 1.5 day/year and the color-change period was postponed by 1 day/year. ${ }^{24,44}$ These findings overall were corroborated by the results derived from the satellite data.

\section{Results and Discussion}

\subsection{Characteristic of Vegetation Cover Changes of the Qinling Mountains From 2001 to 2016}

The vegetation cover changes and spatial distribution of vegetation variability (Fig. 4) of the Qinling Mountains from 2001 to 2016 (Fig. 4) showed that, during this period, except for a few zones that displayed a decreased trend, the mountain range overall manifested increased vegetation coverage; the areas showing increased (or decreased) vegetation coverage accounted for $89.93 \%$ (and $11.07 \%$ ) of the total area, respectively. Among the areas showing increased coverage, $38.57 \%$ displayed significant differences $(P<0.05)$. Notably, the southeastern part of the Qinling Mountains, where the vegetation cover had originally been low, registered a more prominent ascending trend than other parts. This phenomenon could be explained by the unfavorable local conditions that initially prompted policies of returning farmland to forest 


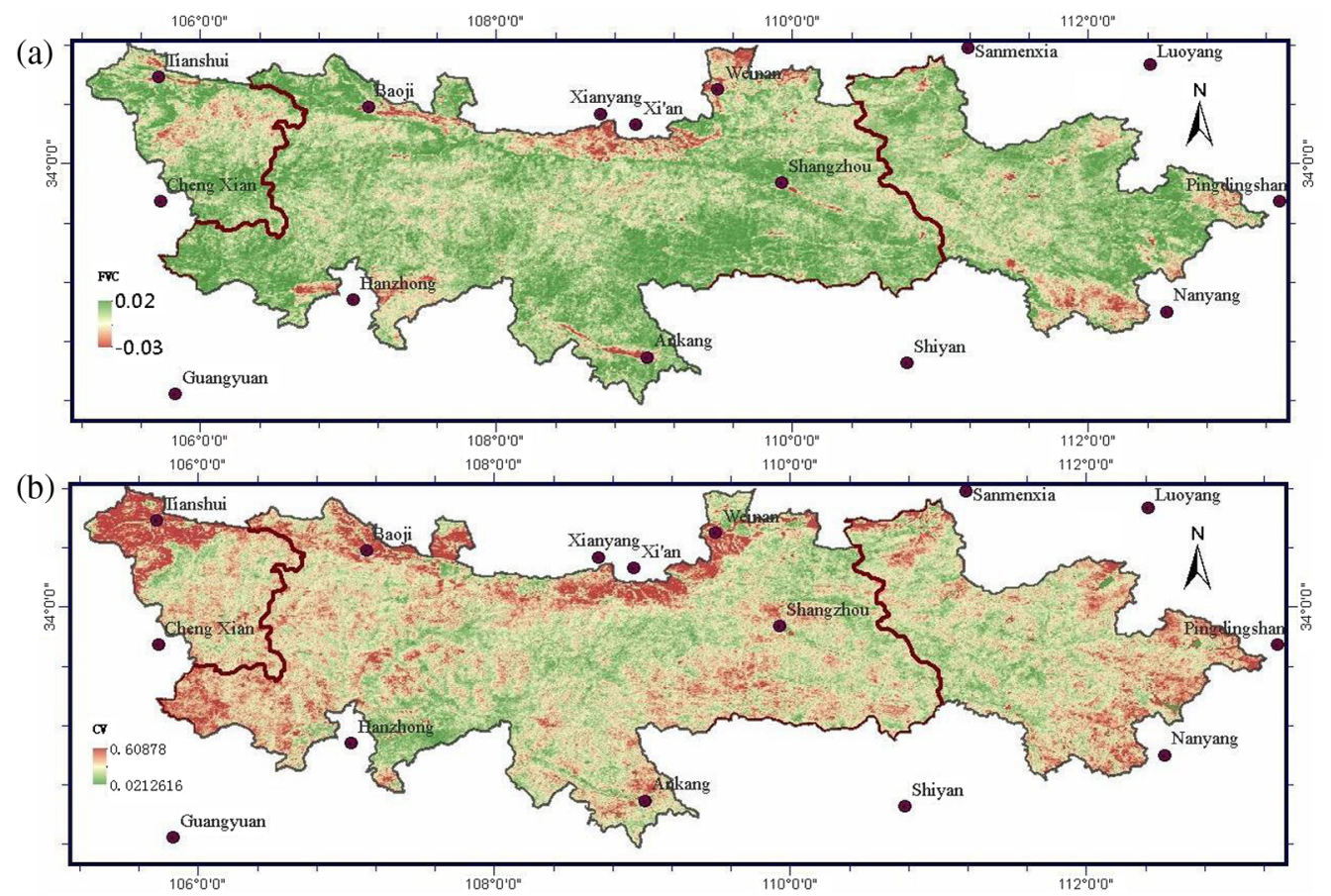

Fig. 4 The multiyear trends and spatial distribution of coefficients of variation of vegetation cover in the Qinling Mountains from 2001 to 2016. (a) Vegetation cover and (b) coefficient of variation.

and grassland and culminated in a remarkable rise in forest concentrations. We then interrogated the vegetation cover data by incorporating the altitude factor and discovered that areas with increased vegetation coverage were mainly the deciduous broadleaf forest belt, with an altitude of 800 to $1500 \mathrm{~m}$. These forests had vegetation coefficients of variation between 0.02 and 0.6 [Fig. 4(b)], indicating considerable spatial variation. Among these forests, those in high-altitude zones or valleys that were the least impacted by human activity showed the highest vegetation stability. On the other hand, the mixed farmland-forest vegetation in the shallow mountains of northern Qinling and the surrounding areas of the mountainous residential communities, which were highly influenced by human presence, exhibited apparent variations [Fig. 4(b)]. Furthermore, the alpine coniferous forests also exhibited a relatively high coefficient of variation as they accommodated great concentrations of Chinese larches (Larix chinensis) and Farges' firs (Abies fargesii), which are highly sensitive to climate change.

\subsection{Spatial Distribution of the Phenological Average Value Over Qinling Mountains from 2001 to 2016}

The spatial distribution of the phenological average value over the Qinling Mountains from 2001 to 2016 is shown in Fig. 5. The data showed that from the alpine areas to farmland areas, the SOG was gradually postponed (decreased in value), the EOG was gradually advanced (decreased in value), and the LOG was gradually shortened. These trends echoed the topography of the Qinling Mountains. The shallow mountainous areas of the northern and southern Qinling foothills and farmland area of the Funiu Mountains had relatively early SOG dates, which began during the first 10 days of March. By contrast, the SOG of the alpine boreal zones was relatively late and began between the 120th and 135th days of the year. The EOG dates mostly appeared between the 270th to 310th days of the year. The EOG was relatively early in the alpine boreal zones but relatively late in the shallow mountainous areas (commonly after the 300th day of the year). The LOG was generally between 150 and 200 days/year and was relatively long in the 

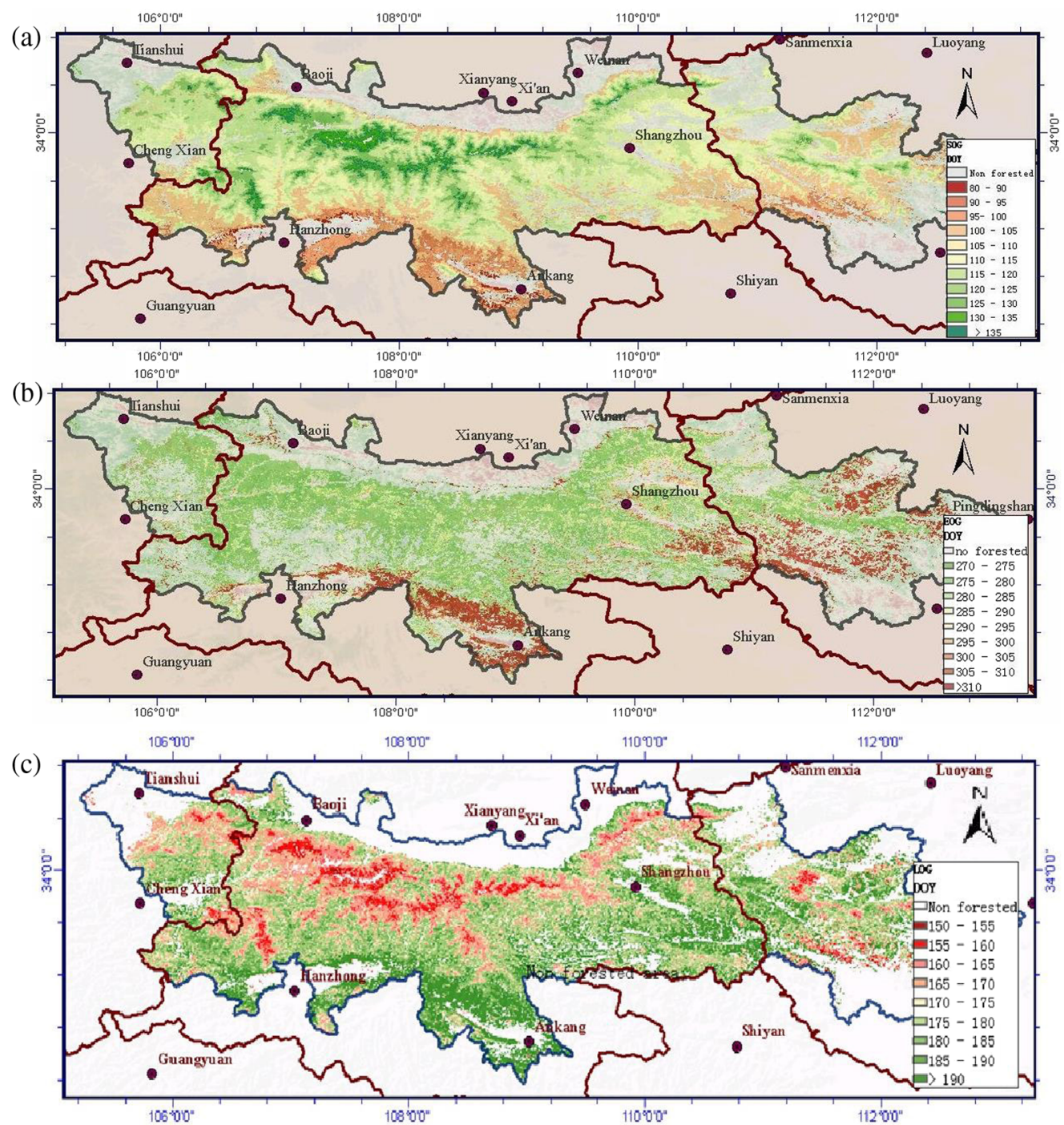

Fig. 5 Spatial distribution of the multiyear means of the forest phenology data in the Qinling Mountains from 2001 to 2016: (a) SOG, (b) EOG, and (c) LOG.

low-altitude areas (over 180 days) but was relatively short in the high-altitude forest areas (between 150 and 170 days). The results also showed that both the SOG and LOG displayed apparent changes in response to rising altitude. However, the areas that were under strong human influence, such as the shallow mountainous areas of the northern Qinling foothills and the surrounding areas of the mountainous residential communities, exhibited no clear correlation between the altitude and phenological changes.

\subsection{Interannual Variation of the Phenological over Qinling Mountains}

The spatial distribution of the multiyear means of the SOG, EOG, and LOG in the Qinling Mountains from 2001 to 2016 is shown in Fig. 6. The results show that the SOG dates in the Qinling Mountains advanced earlier, including $23.45 \%$ of the pixels having $P$ values $<0.01$ (Fig. 7), and about 95\% of the study region showed an advancement of 1 to 2 days/year [Fig. 6(a)], which was more apparent in the high-altitude areas. Nevertheless, an SOG delay was found in the southern and northern low-altitude foothills and the central area of the Funiu Mountain, which overall matched the scope under significant human interference. 


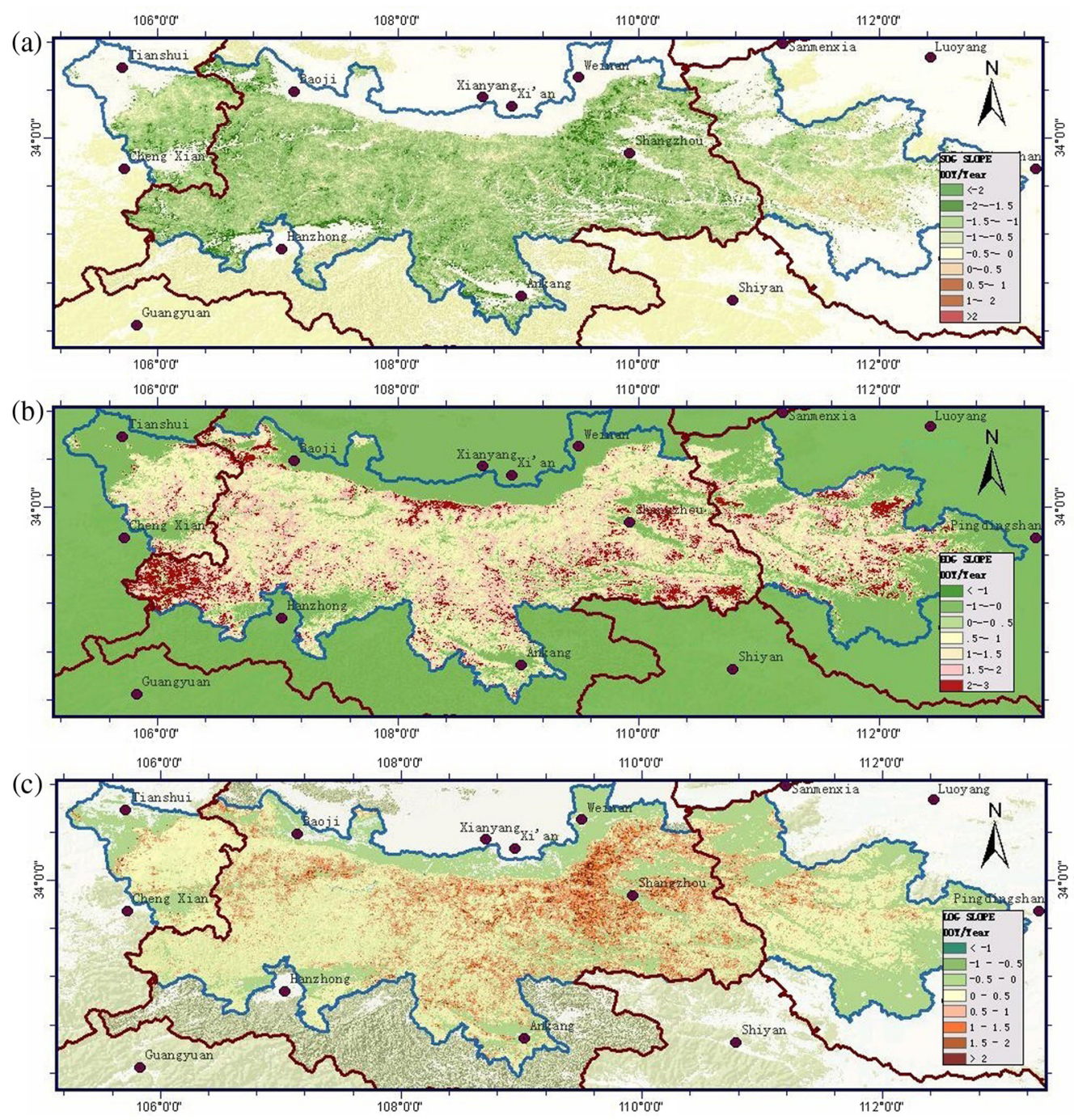

Fig. 6 Spatial distribution of the phytophenological trends in the Qinling Mountains from 2001 to 2016: (a) SOG, (b) EOG, and (c) LOG.

The EOG dates in the Qinling Mountains were delayed [Fig. 6(b)], including 21.45\% of the pixels having $P$ values $<0.01$ (figure not shown here). An EOG delay was apparent ( 2 to 3 days/year) in the northern foothills and eastern mid- to low-altitude areas in the Qinling Mountains [Fig. 6(b)].

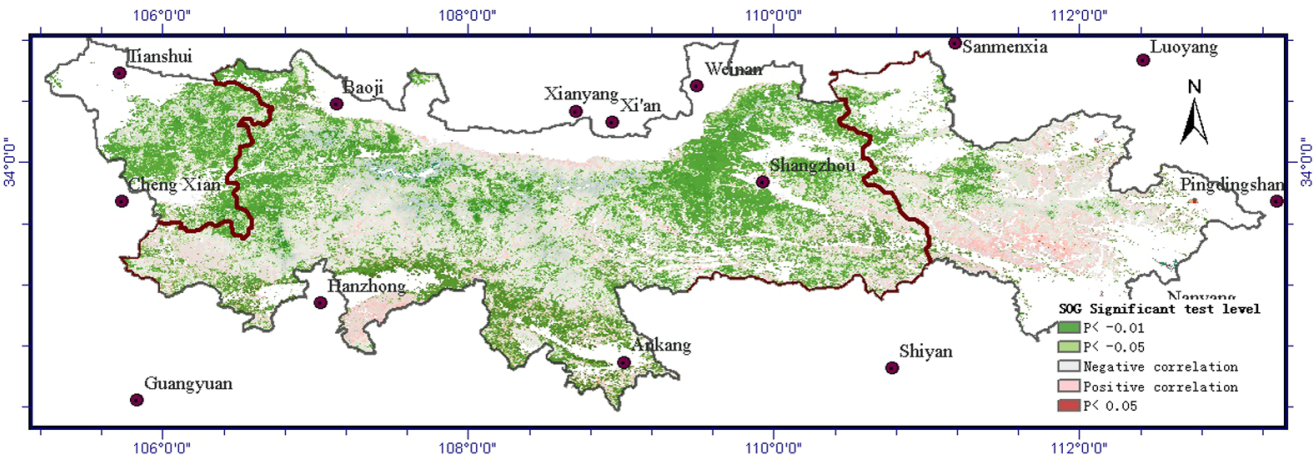

Fig. 7 Significance test results of the SOG trends in the Qinling Mountains from 2001 to 2016. 
During the 2001 to 2016 period, the LOG overall displayed an extending trend in the forest areas of the Qinling Mountains [Fig. 6(c)], including 70\% of the areas that were prolonged by 1 to 3 days/year; in areas with a prolonged LOG, $51 \%$ of the pixels had $P$ values $<0.01$ (figure not shown here). These areas with extended LOGs were mainly distributed in the central and eastern mid- to low-altitude regions. However, $\sim 30 \%$ of the areas in the Qinling Mountains witnessed a shortened LOG ( -1 to 0 days/year), mainly in low-altitude areas that are vulnerable to the influence of human activity.

\subsection{Correlation Between the Phytophenology of the Qinling Mountains and the Threshold Temperature of $10^{\circ} \mathrm{C}$}

Environmental and climate alterations are the major factors contributing to phytophenological changes. Hydrothermal variations were investigated in the Qinling Mountains, showing that the mountain range was experiencing rising temperatures (measured in the spring or as a multiyear average $)^{45-49}$ and reduced precipitation ${ }^{50,51}$ and that these changes mainly took place in the southern and northern foothills. An annual accumulated temperature above $10^{\circ} \mathrm{C}$ is a critical temperature for the majority of plant growth; usually there was an accumulation of daily average temperature above $10^{\circ} \mathrm{C}$, which was defined as an active accumulated temperature. In this study,

(a)
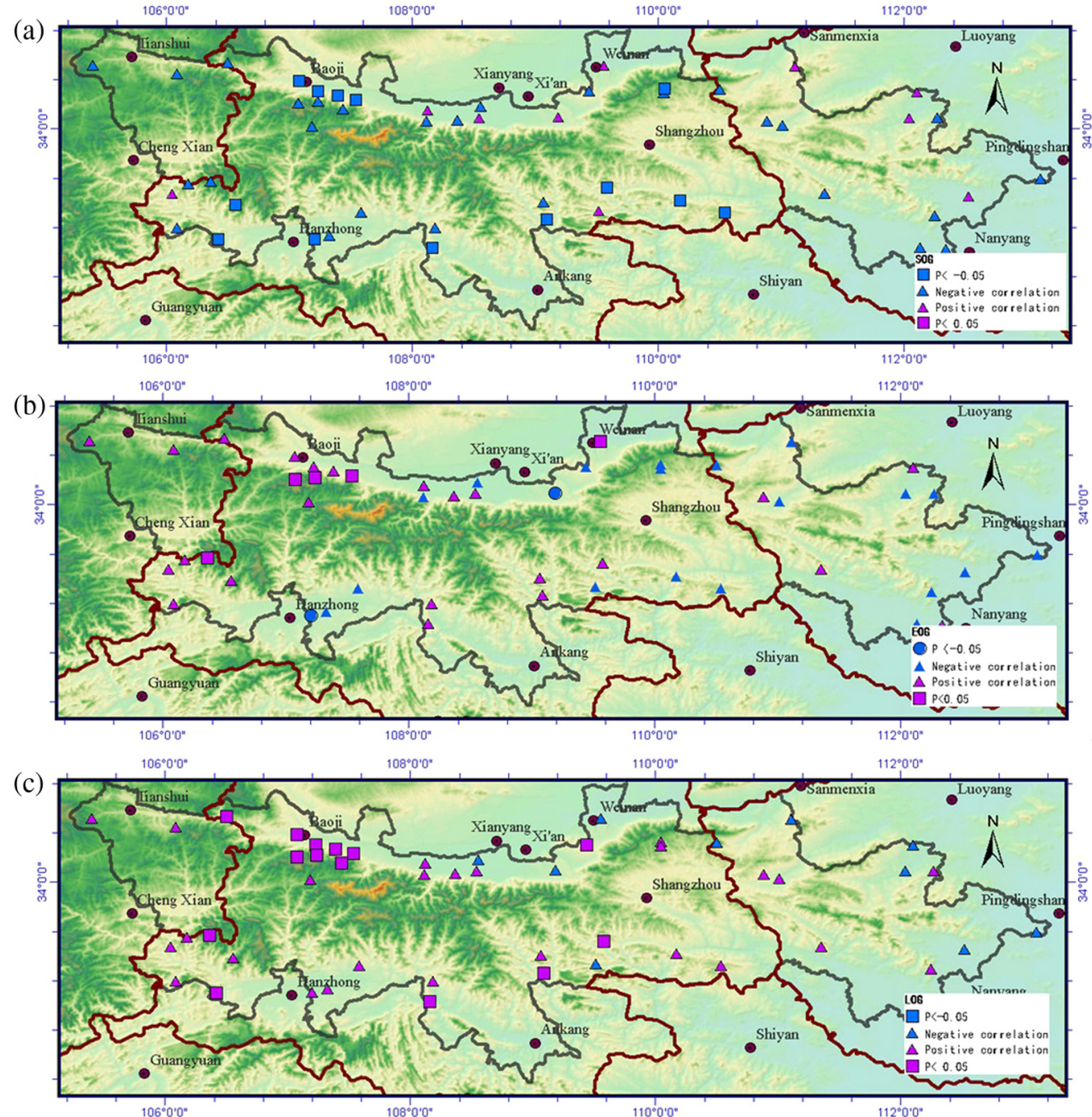

Fig. 8 Significance test results of the correlation analysis between the active accumulated temperature and the phenological parameters: (a) SOG, (b) EOG, and (c) LOG. 
the annual accumulated temperature above $10^{\circ} \mathrm{C}$ was analyzed to understand the real reason of the variation of phenological changes in the Qinling Mountains from 2001 to 2016.

The active accumulated temperature above $10^{\circ} \mathrm{C}$, annual precipitation, and sunshine duration from 2001 to 2016 at 55 stations across the Qinling Mountains was analyzed. Furthermore, the means of the SOG, EOG, and LOG within a 5-km diameter range of each station were extracted. A correlation analysis was then performed for the two groups of data. The results showed that active accumulated temperature exhibited a higher correlation with the SOG, EOG, and LOG than the precipitation and sunshine duration; the three climate parameters had an order of response to the phenological indices of $\geq 10^{\circ} \mathrm{C}$ accumulated temperature $>$ precipitation $>$ sunshine duration. This was consistent with a previous study, ${ }^{52}$ and, collectively, the findings support that global warming is a main factor impacting the phytophenogical changes in the Qinling Mountains. Among the three phenological parameters, the SOG overall showed a negative correlation with the $\geq 10^{\circ} \mathrm{C}$ accumulated temperature [Fig. 8(a)]. There were 13 stations approved by significant testing, mainly distributed in the counties of the northern foothills (e.g., Qianyang, Fengxiang, Qishan, Fufeng, and Huayin) and southern foothills (e.g., Mianxian, Chenggu, Yangxian, Shiquan, Zhen'an, Liuba, Danfeng, and Shangnan), where the altitude is 1000 to $2000 \mathrm{~m}$ and the annual mean of the $\geq 10^{\circ} \mathrm{C}$ accumulated temperature is 4000 to $4500^{\circ} \mathrm{C}$. In these areas, the rising temperature clearly advanced the SOG. By contrast, the SOG was poorly correlated with the $\geq 10^{\circ} \mathrm{C}$ accumulated temperature in the alpine areas, where the annual accumulated temperature was below $4000^{\circ} \mathrm{C}$, as well as in the areas that were under significant human influence, where the annual accumulated temperature was above $4800^{\circ} \mathrm{C}$. In general, the rising temperature showed no apparent effect on the SOG in these areas.

Both the EOG [Fig. 8(b)] and LOG [Fig. 8(c)] overall exhibited a positive correlation with the $\geq 10^{\circ} \mathrm{C}$ accumulated temperature. The LOG showed a higher correlation with the accumulated temperature than the EOG, with 14 stations approved by significant testing. These stations matched well with the stations where the SOG was significantly correlated with the accumulated temperature. Together, these results indicated that the areas with a greater response to the $\geq 10^{\circ} \mathrm{C}$ accumulated temperature were distributed in the southern and northern foothills, where the altitude was between 1000 and $2000 \mathrm{~m}$ and the annual accumulated temperature was between $4000^{\circ} \mathrm{C}$ and $4500^{\circ} \mathrm{C}$, and that the northern foothills displayed greater responsiveness than the southern foothills. In addition, the alpine areas (with an accumulated temperature of $<4000^{\circ} \mathrm{C}$ ) had complicated responses to the phenological changes, which might be attributed to the extraordinary sensitivity of Chinese larches (Larix chinensis) and Farges' firs (Abies fargesii) to temperature changes. The phenological indices in the alpine areas showed no apparent responses to the active accumulated temperature as the climate parameter grew slowly in the alpine areas. Last, stations in the Funiu Mountains in the east, where the annual accumulated temperature is over $4900^{\circ} \mathrm{C}$, also displayed a poor correlation with the threshold temperature, indicating that this region was not significantly impacted by this temperature condition.

\section{Summary and Conclusions}

In this study, the C5 MOD09A1 product from 2001 to 2016 provided by NASA LPACC was used to rebuild the EVI time series. Four reconstruction methods were compared; the maximal slop of alteration method and the threshold method were employed to extract the phenological parameters in the Qinling Mountains.

The results showed that the Whittaker filter was better in the reconstruction of sample plots for shrubland, farmland, and forest than the DL, AG, and HANTS methods. Additionally, the reconstructed curves of the Whittaker filter displayed the lowest deviation from the original EVI data in all three vegetation types in the Qinling Mountains.

There was an increasing trend of vegetation coverage in most regions (about $89.93 \%$ of the monitored areas) from 2001 to 2016 , and only $11.07 \%$ of the study region showed decreased trends. The coefficients of vegetation variation were between 0.02 and 0.6 , and the forests that were less affected by human activity showed the highest vegetation stability. The mixed farmland-forest vegetation in the shallow hills of the northern Qinling Mountains and the surrounding 
areas of mountainous residential communities obviously exhibited alterations with the extraordinary impact of human activity.

The average variation of phenological parameters in the Qinling Mountains indicated that, as the altitude decreased (from the alpine areas to the farmland districts), the SOG was gradually delayed, the EOG was gradually advanced, and the LOG was gradually shortened. These trends were consistent with the local topographical and thermal conditions. Within the Qinling Mountains, the shallow mountainous areas and farmland area of the Funiu Mountains had relatively early SOG dates, which began in the first 10 days of March. By contrast, the SOG of the alpine boreal zones started between the 120th and 135th days of the year. The EOG dates typically started between the 270th and 310th days of the year, which was relatively early for the alpine boreal zones but relatively late in the shallow mountainous areas (typically after the 300th day of the year). The LOG typically lasted between 150 and 200 days/year and was relatively long in the long-altitude areas (over 180 days) but was relatively short in the high-altitude forest areas (between 150 and 170 days).

Time series variation of phenological from 2001 to 2016 showed that the SOG in the Qinling Mountains was earlier, which was more obvious in high-altitude areas (about 1 to 2 days/year), and, for altitude below $500 \mathrm{~m}$, there was a little delay, mostly in the southern and northern foothills and the eastern Funiu Mountains. The EOG showed a delaying trend, which was clear (postponed by 2 to 3 days/year) in the northern slope of Qinling and the eastern mid-tolow-altitude areas. The LOG overall showed a trend of extended duration, with $87.5 \%$ of the forest areas showing a change in the duration of the growth season by -1 to 2 days/year.

The correlation analysis between the climate parameters (i.e., the active accumulated temperature, precipitation, and sunshine duration) and phenological indices (the SOG, EOG, and LOG) in 55 stations across the Qinling Mountains during the 2001 to 2016 period showed that, for the three climate parameters, the active accumulated temperature had the highest correlation with the phenological indices of the SOG, EOG, and LOG, while, for the precipitation and sunshine, duration was relatively low. Global warming was a key factor influencing the phytophenological changes in the Qinling Mountains, as the rising temperature advanced the SOG, delayed the EOG, and prolonged the LOG. This effect was more obvious in the southern and northern slopes of the Qinling Mountains with an altitude of 1000 to $2000 \mathrm{~m}$. However, for the alpine areas, the effect of global warming to the phytophenological change was more complex, which might be related to the low increase of active accumulated temperature and the extraordinary sensitivity of Chinese larches (Larix chinensis) and Farges' firs (Abies fargesii). Stations in the Funiu Mountains in the east part of the Qinling Mountains displayed a poor correlation with the active accumulated temperature, indicating that this region was not significantly impacted by global warming.

\section{Acknowledgments}

This work was supported by the Science and Technology Fund of the Meteorological Bureau of Shaanxi Province (2015-10).

\section{References}

1. Y. Ping and S. Zhang, "Crop identification based on MODIS NDVI time-series data and phenological characteristics," J. Natl. Res. 31(3), 503-513 (2016).

2. Y. He et al., "Vegetation phenological variation and its response to climate changes in Zhejiang Province," J. Natl. Res. 28(2), 220-233 (2013).

3. C. Atzberger and P. H. C. Eilers, "A time series for monitoring vegetation activity and phenology at 10-daily time steps covering large parts of South America," Int. J. Digital Earth 4(5), 365-386 (2011).

4. P. S. A. Beck et al., "Improved monitoring of vegetation dynamics at very high latitudes: a new method using MODIS NDVI,' Remote Sens. Environ. 100(3), 321-334 (2006).

5. T. Sakamoto et al., "A crop phenology detection method using time-series MODIS data," Remote Sens. Environ. 96(3), 366-374 (2005). 
Wang et al.: Spatiotemporal variations of forest phenology in the Qinling Mountains...

6. J. Chen et al., "A simple method for reconstructing a high-quality NDVI time-series data set based on the Savitzky-Golay filter," Remote Sens. Environ. 91(3), 332-344 (2004).

7. Y. Julien and J. A. Sobrino, "Global land surface phenology trends from GIMMS database," Int. J. Remote Sens. 30, 3495-3513 (2009).

8. C. Wang et al., "Temperature sensitivity of spring vegetation phenology correlates to within-spring warming speed over the Northern Hemisphere," Ecol. Indic. 50(3), 62-68 (2015).

9. M. A. White et al., "Inter-comparison, interpretation, and assessment of spring phenology in North America estimated from remote sensing for 1982-2006," Global Change Biol. 15, 2335-2359 (2009).

10. X. Zhang et al., "Monitoring vegetation phenology using MODIS," Remote Sens. Environ. 84, 471-475 (2003).

11. D. Lloyd, "Phenological classification of terrestrial vegetation covers using shortwave vegetation index imagery," Int. J. Remote Sens. 11, 2269-2279 (1990).

12. J. I. Fisher and J. F. Mustard, "Cross scalar satellite phenology from ground, Landsat and MODIS data," Remote Sens. Environ. 109(3), 261-273 (2007).

13. A. Kross et al., "The effect of the temporal resolution of NDVI data on season onset dates and trends across Canadian broadleaf forests," Remote Sens. Environ. 115(6), 1564-1575 (2011).

14. P. M. Atkinson et al., "Inter-comparison of four models for smoothing satellite sensor timeseries data to estimate vegetation phenology," Remote Sens. Environ. 123(8), 400-417 (2012).

15. S. Piao et al., "Net carbon dioxide losses of northern ecosystems in response to autumn warming," Nature 451, 49-52 (2008).

16. S. Fang et al., "Changing Trends and Abrupt Features of Extreme Temperature in Mainland China from 1960 to 2010," Atmosphere 7-22 (2016).

17. J. Y. Zheng, Q. S. Ge, and Z. X. Hao, "Effects of global warming on plant phenological changes for the last 40 years in China," Chin. Sci. Bull. 47(20), 1584-1587 (2002).

18. X. X. Zhang, "Relationships between climate change and vegetation in Beijing using remote sensed data and phonological data," Chin. J. Plant Ecol. 28(4), 499-506 (2004).

19. P. L. Lu, Q. Yu, and Q. T. He, "Responses of plant phenology to climatic change," Acta Ecol. Sin. 26(3), 923-929 (2006).

20. M. Li et al., "Growing-season trends determined from SPOT NDVI in Changbai Mountains, China, 1999-2008," Sci. Geogr. Sin. 31(10), 1242-1248 (2011).

21. Y. He et al., "Vegetation phenological variation and its response to climate changes in Zhejiang province," J. Natl. Res. 28(2), 220-233 (2013).

22. S. Fang et al., "Spectra and vegetation index variations in moss soil crust in different seasons, and in wet and dry conditions," Int. J. Appl. Earth Obs. Geoinf. 38, 261-266 (2015).

23. S. Zhong, J. Y. Zheng, and Q. S. Ge, "Change of autumnal leaf coloring of woody plants in Eastern China for the last 40 years," Chin. J. Agrometeorol. 31(01), 1-4 (2010).

24. C. H. Wang et al., "Phenological changes of ligneous plants in Xi' an Botanic Garden in last 15 years," Chin. J. Agrometeorol. 27(4), 261-264 (2006).

25. B. Xie et al., "Monitoring vegetation phenology and their response to climate change on Chinese Loess Plateau based on remote sensing," Trans. Chin. Soc. Agric. Eng. 31(15), 153-160 (2015).

26. D. K. Li, J.-Z. Fan, and W.-T. Quan, "Analysis of vegetation degradation and its driving factors in Shaanxi Province," Chin. J. Ecol. 34(10), 2907-2913 (2015).

27. H. Song, K. Liu, and Y. N. Fan, "Analysis on spatial and temporal changes of forest degradation in Qinling Mountainous region," Popul. Res. Environ. 5, 153-157 (2016).

28. H. M. Xia et al., "Spatiotemporal variations of forest phenology in the Qinling zone based on remote sensing monitoring, 2001-2010," Prog. Geogr. 34(10), 1297-1305 (2015).

29. Y. N. He, "Research on the variation of vegetation phenology in the Qinling Mountains based on remote sensing and in situ observations," MSc Thesis, Northwest University, Xi'an, China (2012).

30. Z. Han and R. Zhiyuan, "Remote sensing analysis of vegetation phenology characteristics in Shaanxi province based on Whittaker smoother method," J. Desert Res. 35(4), 901-906 (2015). 
31. Y. B. Zhang et al., "Spatial distribution patterns of species richness and hotspots of protected plants in Qinling Mountain," Acta Ecol. Sin. 34(8), 2109-2117 (2014).

32. S. H. Shang and H. Xing, "Comparison of vertical distribution of vegetation on the north and south slope of Qinling Mountains," Garden Ecol. 1(1), 114-115 (2016).

33. J. Yang et al., "Analyses on MODIS-NDVI index saturation in Northwest China," Plateau Meteorol. 27(4), 896-903 (2008).

34. Y. N. Liu, F. Xiao, and Y. Du, "Analysis of four time series EVI data reconstruction methods," Acta Ecol. Sin. 36(15), 4672-4679 (2016).

35. C. Q. Song et al., "Comparison of three NDVI time-series fitting methods based on TIMESAT-taking the grassland in northern Tibet as case," Remote Sens. Technol. Appl. 26(2), 147-155 (2011).

36. J. Chen et al., "A simple method for reconstructing a high-quality NDVI time-series data set based on the Savitzky-Golay filter," Remote Sens. Environ. 91(3-4), 332-344 (2004).

37. H. Y. Li, Y. W. Xie, and M. G. Ma, "Reconstruction of temporal NDVI dataset: evaluation and case study," Remote Sens. Technol. Appl. 24(5), 596-602 (2009).

38. Q. K. Wang et al., "Comparison on three algorithms of reconstructing time-series MODISEV," J. Geo-Inf. Sci. 17(6), 732-741 (2015).

39. H. H. Zhou et al., "Comparison and analysis of remotely sensed time series of reconstruction models at various intervals," J. Geo-Inf. Sci. 18(10), 1410-1417 (2016).

40. L. I. Lingling, L. I. Liangyun, and H. U. Yong, "Assessment and inter-comparison of satellite-derived start-of-season (SOS) measures in Eurasia for 1982-2006," Prog. Geogr. 31(11), 1433-1442 (2012).

41. M. J. Ding et al., "Spatiotemporal variation in alpine grassland phenology in the QinghaiTibetan Plateau from 1999 to 2009," Chin. Sci. Bull. 58(3), 396-405 (2013).

42. F. A. N. Deqin et al., "Review of influencing factors of accuracy of plant phenology monitoring based on remote sensing data," Prog. Geogr. 35(3), 304-319 (2016).

43. P. Y. Cao et al., "Review on vegetation phenology observation and phenological index extraction," Adv. Earth Sci. 31(4), 365-376 (2016).

44. J. Bai et al., "Relationship between woody plants phenology and climate factors in Xi'an, China," Chin. J. Plant Ecol. 34(11), 1274-1282 (2010).

45. S. Li, J. P. Yan, and J. Wan, "The characteristics of temperature change in Qinling Mountains," Sci. Geogr. Sin. 32(7), 853-858 (2012).

46. Z. F. Wei, Z. Y. Ren, and C. Zhang, "Impact of climate on vegetation phenology on Loess Plateau in Shaanxi-Gansu-Ningxia Region during 1999-2010," Bull. Soil Water Conserv. 34(5), 232-236 (2014).

47. Z. Wang et al., "Effects of urbanization on temperatures over the Qinling Mountains in the past 50 years," Q. J. Appl. Meteorol. (1), 84-94 (2016).

48. Z. Wang, Y. Peng, and N. Wei, "Variation trends of the extreme temperature and its relationship with regional warming in the south and north sides of the Qinling Mountain during 1961-2012," Arid Weather 34(2), 269-275 (2016).

49. Q. Zhou, J. J. Bian, and J. Y. Zheng, "Variation of air temperature and thermal resources in the northern and southern regions of the Qinling Mountains from 1951 to 2009," Acta Geogr. Sin. 66(9), 1211-1218 (2011).

50. Y. Peng et al., "Characteristics and reasons of local change of precipitation over Shaanxi during 1960-2012," Plateau Meteorol. 35(4), 1050-1059 (2016).

51. W. Xiaoling and R. Yan, "Analysis of precipitation differences and their local causes in the last 50 years around the Qinling Mountains," Clim. Environ. Res. 17(6), 911-918 (2012).

52. N. Guo et al., "The relationship between NDVI and climate elements for 22 years in different vegetation areas of northwest China," J. Plant Ecol. 32(2), 319-327 (2008).

Zhao Wang started as engineer with application of satellite remote sensing in 2002. His research interests include air quality monitoring, vegetation monitoring through remote sensing satellites. Currently, he is a senior engineer of Shaanxi Remote Sensing Information Center for Agriculture.

Biographies for the other authors are not available. 